\title{
Association between risk of preeclampsia and maternal plasma trimethylamine-N-oxide in second trimester and at the time of delivery
}

\section{Xin Huang}

Hunan Normal University

\section{Zuodong Li}

Hunan Normal University

\section{Zhou Gao}

central south univsersity

Dapeng Wang

Guizhou Medical University

Xiaohui Li

Central south university

\section{Ying Li}

Central South university

\section{Chunmei Mi}

\section{Central South University}

Jun Lei ( $\square$ junlei.xy3yy@hotmail.com )

Central South University Third Xiangya Hospital https://orcid.org/0000-0003-3192-9560

\section{Research article}

Keywords: Trimethylamine-N-oxide, preeclampsia, early onset preeclampsia, sever preeclampsia, nested case-control study

Posted Date: May 14th, 2020

DOI: https://doi.org/10.21203/rs.3.rs-18239/v2

License: (c) (i) This work is licensed under a Creative Commons Attribution 4.0 International License. Read Full License

Version of Record: A version of this preprint was published at BMC Pregnancy and Childbirth on May 19th, 2020. See the published version at https://doi.org/10.1186/s12884-020-02997-7. 


\section{Abstract}

Background: The data on the association between the microbiota-dependent metabolite trimethylamineN-oxide (TMAO) during pregnancy and risk of preeclampsia (PE) is limited. Methods: We, therefore, conducted a prospective nested case control study during Sep 2017 to Dec 2018 to examine the association between plasma TMAO measured during pregnancy and the risk of PE. Total of 17 patients diagnosed with EOPE (early onset PE), 49 with LOPE (late onset PE) and 198 healthy controls were enrolled. Blood samples were collected at 15-23 gestational weeks and time at delivery. The Logistic regression model was used to assess the odds ratio (OR) and 95\% confidence interval (CI) for TMAO and risk of $P E, E O P E, L O P E$, mild $P E$, and severe $P E$.

Results: We found that the mean TMAO levels of overall subjects in the second trimester (T2) and at the time of delivery (TD) were $90.39 \mu \mathrm{g} / \mathrm{m}^{3}(\mathrm{SD}=45.91)$ and $175.01 \mu \mathrm{g} / \mathrm{m}^{3}(\mathrm{SD}=160.97)$, respectively. No significant spearman correlation was found between the TMAO in those two periods ( $p>0.05)$. T2 TMAO was not significantly associated with risk of PE or risk of any PE subtypes $(p>0.05)$. However, TD TMAO was significant associated with risk of PE, EOPE and severe PE (adjusted OR and $95 \% \mathrm{Cl}$ were 1.24(1.09, $1.40), 1.62(1.29,2.03)$, and $1.41(1.17,1.70))$ per $50 \mu \mathrm{g} / \mathrm{m}^{3}$ increment, respectively).

Conclusion: Our study found that plasma TMAO level would alter over the course of pregnancy. The major role of TMAO in PE development might be in the accelerating process not in the initiation.

\section{Background}

Preeclampsia (PE) complicates $2-5 \%$ of pregnancies and is a major cause of maternal, fetal, and neonatal morbidity and mortality ${ }^{[1]}$. Recent researchers found that the intestinal microbiota plays an important role in the development of PE ${ }^{[2-4]}$. However, it is still unclear how intestinal microbiota participates in the pathogenesis of $\mathrm{PE}$.

Microbes that live in the gut could produce a vast number of metabolites, many of which are dependent on the diet of the host ${ }^{[5]}$ and absorbed into the circulation, chemically modified by the host, and eventually exert their functions in host physiology and pathophysiology ${ }^{[6]}$. Food containing phosphatidylcholine, choline, and carnitine, can be used by gut microbes as a carbon fuel source and high levels of trimethylamine (TMA) would be metabolized at the same time ${ }^{[7,8]}$. TMAs which are carried via the portal circulation to the liver, are oxidized further into TMA-N-oxide (TMAO) by a family of enzymes, flavin monooxygenases (FMOs) ${ }^{[7,8]}$. Plasma TMAO levels have been associated with risk of atherosclerotic cardiovascular disease (ASCVD) in multiple distinct clinical studies ${ }^{[8-11]}$. The underlying mechanisms might involve increased coronary atherosclerotic plaque burden ${ }^{[8]}$, accelerated endothelial dysfunction ${ }^{[9]}$, and risk for thrombotic events ${ }^{[11]}$ induced by TMAO in human subjects.

PE shared similar mechanisms with ASCVD whereby both of them involved oxidative stress and endothelial dysfunction ${ }^{[12-15]}$. They have common risk factors such as obesity, diabetes, and 
hypertension ${ }^{[13-15]}$. Recently, a study conducted on the reduced uterine perfusion pressure (RUPP) rat model implies that TMAO was also involved in the development of PE ${ }^{[16]}$. However, the role of TMAO in PE development as an initiator or a trigger could not be answered by RUPP model. Moreover, the data on human beings is still lacking. We, therefore, conducted a prospective nested case control study in Changsha, China, to examine the association between plasma TMAO measured during pregnancy and the risk of $\mathrm{PE}$.

\section{Methods}

\section{Study population}

We enrolled subjects from an ongoing prospective cohort which aimed at maternal depression screening and associated risk factors. The study was performed at the Third Xiangya Hospital of Central South University (TXYHCSU) from September 2017 until December 2020. The enrollment criteria for the cohort were singleton pregnancy, $\geq 20$ years old, with no history of mental disease. All qualified pregnant women at 12-14 weeks gestation were recruited when they attended first prenatal visit and would be followed till 6 weeks after delivery. In the present nested case-control study, all patients in the cohort diagnosed with PE and have delivered before the end of 2018, with no history of chronic diabetes mellitus, renal disease, or other chronic cardiovascular disease were recruited in case group. We matched each PE case with 3 controls who were normotensive singleton pregnant women, without chronic diseases, with similar age (within \pm 3 years), and blood samples were collected. Finally, 17 patients diagnosed with EOPE, 49 with LOPE and 198 healthy controls were enrolled.

\section{Data collection and diagnosis criteria}

The study protocol were reviewed and approved by the Ethical and Confidentiality Committee of Central South University. All selected participants were informed about the purpose of the study. After obtaining written consent, an in-person interview was conducted at baseline by trained nurses using a standardized and structured questionnaire to collect information on demographics, medical history and lifestyle factors. Enrolled subjects were followed at 15-23 gestational weeks, 24-32 gestational weeks, time at delivery, 2-4 weeks and 6 weeks after delivery. At the 15-23 gestational weeks (second trimester, T2) and time at delivery (TD), $5 \mathrm{ml}$ fasting blood samples were collected in tubes with heparin as anticoagulant and centrifuged at $1620 \mathrm{~g}$ at $4^{\circ} \mathrm{C}$ for $5 \mathrm{~min}$. Then, the plasma was detached and stored at $-80^{\circ} \mathrm{C}$ for subsequent analysis of TMAO. Information on maternal complications was abstracted from medical charts. PE was diagnosed as hypertension concurrent with proteinuria $(\geq 1+$ on dipstick in two urine samples) after 20 weeks of gestation. PE was further classified as mild PE (raised blood pressure $\geq 140 / 90 \mathrm{mmHg}$ and $<160 / 110 \mathrm{mmHg}$, proteinuria $\geq 1+$ and $<2+$ on dipstick in two urine samples, without symptoms of severity), severe $\mathrm{PE}$ (raised blood pressure $\geq 160 / 110 \mathrm{mmHg}$, proteinuria $\geq 2+$ on dipstick in two urine samples, with symptoms of severity such as headache, blurred vision, epigastric burning pain, decreased urine output, decreased or absent fetal kick etc.), early onset PE (EOPE, 
diagnosed before 34 weeks of gestation), or late onset PE (LOPE, diagnosed at or after 34 weeks of gestation).

\section{Plasma TMAO concentration assays}

We measured TMAO concentrations in Hunan Key Laboratory for Bioanalysis of Complex Matrix Samples using ultrahigh performance liquid chromatography-tandem mass spectrometry (UHPLCMS/MS) as described by Awwad HM et al ${ }^{[17]}$ and the details was described in the supplementary (Supplementary 1). In brief, all the samples were kept in the auto-sampler at $10^{\circ} \mathrm{C}$ TMAO and d9-TMAO were monitored in positive-ion mode with multiple reaction monitoring of precursor and characteristic production transitions of $\mathrm{m} / \mathrm{z} 76.3 \rightarrow 58.4$ and $85.1 \rightarrow 66.3$, respectively. Various concentrations of nonisotopically labeled TMAO were mixed with a fixed amount of internal standard d9-TMAO to prepare the calibration curves for quantification of plasma TMAO. For quality assurance, 8 different quality-control samples with TMAO concentrations ranging between 2 and $500 \mathrm{ng} / \mathrm{mL}$ were used for the evaluation of accuracy and precision. Samples with TMAO concentration exceeding $500 \mathrm{ng} / \mathrm{mL}$ were diluted and the final concentrations were calculated with use of appropriate dilution factor. The accuracy of qualitycontrol samples was within the range of $85-105 \%$ of the nominal values, the intra- and inter assay coefficient of variations (CVs) were all below $6 \%$, and the absolute recovery was between $85 \%$ and $106 \%$. All of the assays were performed without knowledge of PE status.

\section{Statistical Analysis}

The distribution of maternal characteristics was compared between PE and control groups by Chisquared tests. Prior to describe the distribution of TMAO concentration, the normality assumption of residuals was tested using Shapiro-Wilk test. However, the significant departures from normality were observed $(p<0.05)$. Median and range were used to describe the distribution of TMAO among overall subjects. Individual change of TMAO was TD TMAO minus the T2 TMAO. The spearman correlation between the change of plasma TMAO and TMAO in T2 or TD was further estimated. Unconditional logistic regression model was used to calculate odds ratios (OR) and $95 \%$ confidence intervals $(\mathrm{Cl})$ for the associations between TMAO and risk of PE, EOPE, LOPE, mild PE, and severe PE, by different times. The exposure of TMAO was evaluated in two ways: 1 ) categorized by quartiles; 2 ) treated as a continuous variable, and results were presented for the change in health outcome per $50 \mu \mathrm{g} / \mathrm{m}^{3}$. Potential confounding variables included in multivariate models were year of education $(<12, \geq 12)$, active and/or passive smoking during pregnancy (yes or no), pre-pregnancy BMI $\left(<18.5,18.5-22.9\right.$, and $\left.\geq 23 \mathrm{~kg} / \mathrm{m}^{2}\right)$, and fetal gender (male or female). Statistical significance was all assessed at the two-tailed 0.05 level. All analyses were performed using SAS, version 9.2 (SAS Institute, Inc., Cary, NC).

\section{Results}

\section{General characteristics}


Compared to controls, women with PE were more likely to be less educated $(p=0.040)$. There were no significant differences in the distribution of pre-pregnancy BMI, exposure to smoking during pregnancy and fetal gender between preeclampsia and controls (Table 1).

\section{Distribution of maternal plasma TMAO}

Table 2 presented distribution of maternal plasma TMAO concentration in T2 and TD for the overall study subjects. The median TMAO concentration for T2 and TD were $84.80 \mu \mathrm{g} / \mathrm{m}^{3}$ and $138.60 \mu \mathrm{g} / \mathrm{m}^{3}$, respectively. More than $75 \%$ subjects showed increased TMAO concentration as they progressed from T2 to TD (Table 2). However, no significant spearman correlation was found between the plasma TMAO in those two periods ( $p=0.157$, Table 3 ). Direct comparison on TMAO between control and PE was listed in the supplementary (Table S1) and the results were similar to the following logistic regression analysis (Table 4 and Table 5).

\section{Association between plasma TMAO and PE}

With adjustment for education, smoking during pregnancy, pre-pregnancy BMl, and fetal gender, T2 TMAO was not significantly associated with risk of PE or risk of any PE subtypes ( $p$-trend $>0.05$, Table 4 ). However, TD TMAO was significant positively associated with risk of PE, EOPE and severe PE (adjusted OR and $95 \% \mathrm{Cl}$ were $1.24(1.09,1.40), 1.62(1.29,2.03)$, and $1.41(1.17,1.70))$ per $50 \mu \mathrm{g} / \mathrm{m}^{3}$ increment, respectively) (Table 5). Comparing the highest TMAO exposure with the lowest quartile, the adjusted ORs for PE were 4.25 (95\% Cl: 1.62, 11.10, $p$-trend= 0.018); for EOPE 14.86 (95\% Cl: 1.66, 129.85, $p$-trend= 0.010); and for severe PE were 14.37 (95\% Cl: 1.74, 118.77, $p$-trend= 0.019).

\section{Discussion}

\section{Main findings}

Our nested case-control study found that the maternal plasma TMAO would alter over the course of pregnancy. Maternal plasma TMAO in second trimester was not associated with PE. However, the plasma TMAO level among PE, EOPE and severe PE patients was significantly increased the time of delivery.

\section{Interpretation}

Circulating TMAO is formed via a two-step metaorganismal pathway ${ }^{[7,8]}$. Specifically, following food intake, gut microbes form TMA, and then host hepatic FMOs catalyze the conversion of TMA into TMAO $[7,8]$. Interventions involving major gut microbiota or dietary alterations would lead to TMAO alterations, such as antibiotics, diet intervention, and bariatric surgery ${ }^{[18-21]}$. Our findings suggested that TMAO level would also alter during natural pregnancy. To the best of our knowledge, our work is the first longitudinal study to investigate TMAO levels within individual pregnant women from T2 to TD. Koren et al ${ }^{[22]}$ had followed 91 pregnant women and found that the gut microbial community composition was profoundly altered over the course of pregnancy. Though food consumption pattern does not change significantly 
throughout the pregnancy period, women were more likely tended to consume more red meat and eggs during pregnancy ${ }^{[23]}$. More than $75 \%$ subjects showed increased TMAO as T2 progressing to TD and the degree of alteration was not related to the T2 TMAO level. Thus, we speculated that altered gut microbiota components, plus increased red meat and eggs consumption during pregnancy might contribute to the observed TMAO alteration in our study. However, we do not have any data about food consumption or gut microbiota variation occurring in the study subjects during the progress of pregnancy, the underlying mechanisms need further validation.

Plasma TMAO levels have been observed associated with risk of ASCVD ${ }^{[12-15]}$, kidney failure ${ }^{[24]}$, cancer ${ }^{[25]}$ and gestational diabetes mellitus ${ }^{[26]}$ in clinical studies. Recently, a study conducted on the RUPP rat model implies that TMAO was also involved in the development of PE ${ }^{[16]}$. The findings in the present study supported the finding that PE patients had elevated TD TMAO. However, elevated TMAO in T2 was no associated with PE. And elevated TD TMAO was only found in severe PE but not mild PE patients. The difference in those associations might imply a major role of TMAO in PE progression but not in PE initiation. In consistence with our findings, Wang et al ${ }^{[8]}$ found exacerbated atherosclerotic lesions after high TMAO exposure which is the major pathogenic events in preeclampsia. Additionally, in preeclampsia, the coagulation and fibrinolytic cascades are highly activated, accompanied by pathological blood rheology and endothelial dysfunction ${ }^{[13]}$. Studies conducted by Chen et al ${ }^{[16]}$ and Seldin et al ${ }^{[27]}$ indicating promoted recruitment of activated leukocytes to endothelial cells by elevated TMAO exposure. In a recent issue of Cell, Zhu et al ${ }^{[11]}$ also confirmed the role of TMAO in thrombosis was enhancing platelet hyper-reactivity.

LOPE and EOPE are two distinct phenotypes of PE with different mechanisms ${ }^{[28]}$. Our study confirmed this hypothesis, finding association only existing between maternal plasma TMAO and EOPE. EOPE appears to be more related to placental disorder ${ }^{[29]}$. However, LOPE seems to be more linked to maternal constitutional factors ${ }^{[28]}$. We speculated that elevated TMAO exposure might aggravate the aberrant spiral artery remodeling and poor placentation. The specific mechanism requires further research.

\section{Strengths and limitations}

Strengths and limitations should be considered when interpreting the study findings. The nested case control study with prospective design allowed us observing the TMAO variation during pregnancy in the same individual. Information on maternal complications was obtained from medical records, which minimized the potential misclassification of the outcomes. Furthermore, we have data on maternal education, smoking during pregnancy, pre-pregnancy BMI, and fetal gender which allowed adjusting for several important potential confounding factors. However, the limitation of our study should be considered when interpreting the study findings. In present study, we have only accessed the plasma TMAO in second trimester and at the time of delivery. The distribution and alteration of TMAO in other period, such as, preconception, the first trimester and postpartum need further investigation. The TMAO level was associated the various factors including diet pattern, gut microbes, liver function and FMOs 
genotype ${ }^{[7,8,22]}$, however their associations with PE were not discussed at present study. The sample size of our study is small and the replication of our findings in other independent population is needed.

\section{Conclusion}

Maternal plasma TMAO would alter over the course of pregnancy. Maternal plasma TMAO in second trimester was not associated with PE. However, the plasma TMAO level among PE patients was significantly increased at the time of delivery. The major role of TMAO in PE development was in the accelerating process not in the initiation.

\section{Declarations}

\section{Ethical approval and consent to participate:}

This study was reviewed by the Ethical and Confidentiality Committee of Central South University (TXYHCSU -2017-33, approved on 5th Mar 2017). Written consent has been signed by all participants. All personal information has been recoded with initials or numbers which guaranteed no information of the participants can be identified in data analysis.

\section{Consent for publication:}

Not applicable.

\section{Availability of data and materials}

The datasets used and analyzed during the current study are available from the corresponding author on reasonable request.

\section{Competing interests:}

The authors declare that they have no conflicting interests.

\section{Funding:}

This work was funded by National Natural Science Foundation of China (Grant \# 81872685, \#81874267 and \#901821882), Key Laboratory of Environmental Pollution Monitoring and Disease Control, Ministry of Education, Guizhou Medical University (\#GMU-2017-HJZ-05). None of the funding that we had received plays role in the design of the study, data collection, analyzing and interpretation of data, or writing the manuscript.

\section{Authors' contributions:}

XH: funding acquisition, methodology, writing original draft preparation; ZL: formal analysis; ZG: investigation; DW: experimental work; XL experimental work; YL: investigation and formal analysis; CM: 
supervision, investigation; JL: writing reviewing and editing. All authors have read and approved the manuscript.

\section{Acknowledgements:}

The first author Xin Huang was funded by China Scholarship Council and Hunan Provincial Education Department while conducting this study (File No. 201908430273).

\section{References}

[1] Backes CH, Markham K, Moorehead P, Nankervis CA, Giannone PJ. Maternal preeclampsia and neonatal outcomes. Journal of pregnancy. 2011; 2011: 214365.

[2] Liu J, Yang H, Yin Z, Jiang X, Zhong H, Qiu D, et al. Remodeling of the gut microbiota and structural shifts in Preeclampsia patients in South China. Eur J Clin Microbiol Infect Dis. 2017; 36(4):713-719.

[3] Brantsaeter AL, Myhre R, Haugen M, Myking S, Sengpiel V, Magnus P, et al. Intake of probiotic food and risk of preeclampsia in primiparous women: the Norwegian Mother and Child Cohort Study. Am J Epidemiol. 2011;174(7):807-15.

[4] Griffin C. Probiotics in obstetrics and gynaecology. Aust N Z J Obstet Gynaecol. 2015;55(3):201-9.

[5] Tremaroli V, Backhed F. Functional interactions between the gut microbiota and host metabolism. Nature 2012; 489(7415): 242-9.

[6] Neish AS. Microbes in gastrointestinal health and disease. Gastroenterology. 2009;136(1):65-80.

[7] Koeth RA, Wang Z, Levison BS, Buffa JA, Org E, Sheehy BT, et al. Intestinal microbiota metabolism of L-carnitine, a nutrient in red meat, promotes atherosclerosis. Nat. Med. 2013, 19: 576-585.

[8] Wang Z, Klipfell E, Bennett BJ, Koeth R, Levison BS, DuGar B, et al. Gut flora metabolism of phosphatidylcholine promotes cardiovascular disease. Nature 2011; 472(7341): 57-63.

[9] Ma G, Pan B, Chen Y, Guo C, Zhao M, Zheng L, et al. Trimethylamine N-oxide in atherogenesis: impairing endothelial self-repair capacity and enhancing monocyte adhesion. Biosci Rep. 2017;37(2).

[10] Wang Z, Roberts AB, Buffa JA, Levison BS, Zhu W, Org E, et al. Non-lethal Inhibition of Gut Microbial Trimethylamine Production for the Treatment of Atherosclerosis. Cell. 2015;163(7):1585-95.

[11] Zhu W, Gregory JC, Org E, Buffa JA, Gupta N, Wang Z, et al. Gut Microbial Metabolite TMAO Enhances Platelet Hyperreactivity and Thrombosis Risk. Cell. 2016;165(1):111-124.

[12] Staff AC, Dechend R, Redman CW. Review: Preeclampsia, acute atherosis of the spiral arteries and future cardiovascular disease: two new hypotheses. Placenta. 2013;34 Suppl:S73-8. 
[13] ACOG. Hypertension in Pregnancy: Executive Summary. Obstetrics \& Gynecology. 2013;122(5):112231.

[14] Belo L, Santos-Silva A, Quintanilha A, Rebelo I. Similarities between pre-eclampsia and atherosclerosis: a protective effect of physical exercise? Current medicinal chemistry. 2008;15(22):22239 .

[15] Lusis AJ. Atherosclerosis. Nature. 2000;407(6801):233-41.

[16] Chen H, Li J, Li N, Liu H, Tang J. Increased circulating trimethylamine N-oxide plays a contributory role in the development of endothelial dysfunction and hypertension in the RUPP rat model of preeclampsia. Hypertens Pregnancy. 2019; 38(2):96-104.

[17] Awwad, HM, Geisel J, Obeid R. Determination of trimethylamine, trimethylamine $\mathrm{N}$-oxide, and taurine in human plasma and urine by UHPLC-MS/MS technique. Journal of Chromatography B, 2016;1038: $12-18$.

[18] Tang WH, Wang Z, Levison BS, Koeth RA, Britt EB, Fu X, et al. Intestinal microbial metabolism of phosphatidylcholine and cardiovascular risk. N Engl J Med 2013; 368:1575-1584.

[19] Stella C, Beckwith-Hall B, Cloarec O, Holmes E, Lindon JC, Powell J, et al. Susceptibility of human metabolic phenotypes to dietary modulation. J Proteome Res, 2006; 5(10): 2780-2788.

[20] Trøseid, M, Hov JR, Nestvold TK, Thoresen H, Berge RK, Svardal A, et al. Major Increase in MicrobiotaDependent Proatherogenic Metabolite TMAO One Year After Bariatric Surgery. Metabolic Syndrome and Related Disorders, 2016; 14(4):197-201.

[21] Tremaroli V, Karlsson F, Werling M, StåhIman M, Kovatcheva-Datchary P, Olbers T, et al. Roux-en-Y gastric bypass and vertical banded gastroplasty induce long-term changes on the human gut microbiome contributing to fat mass regulation. Cell Metab 2015;22:228-238.

[22] Koren O, Goodrich JK, Cullender TC, Spor A, Laitinen K, Bäckhed HK, et al. Host Remodeling of the Gut Microbiome and Metabolic Changes during Pregnancy, Cell, 2012; 150(3): 470-480.

[23] Cuco G, Fernandez-Ballart J, Sala J, Viladrich C, Iranzo R, Vila J, et al. Dietary patterns and associated lifestyles in preconception, pregnancy and postpartum. Eur J Clin Nutr 2006; 60: 364-71.

[24] Stubbs JR, House JA, Ocque AJ, Zhang S, Johnson C, Kimber C, et al. Serum trimethylamine-N-oxide is elevated in CKD and correlates with coronary atherosclerosis burden. J Am Soc Nephrol 2016; 27: 30513.

[25] Xu R, Wang Q, Li L. A genome-wide systems analysis reveals strong link between colorectal cancer and trimethylamine N-oxide (TMAO), a gut microbial metabolite of dietary meat and fat. BMC Genomics 2015; 16 (Suppl 7):S4. 
[26] Li P, Zhong C, Li S, Sun T, Huang H, Chen X, et al. Plasma concentration of trimethylamine-N-oxide and risk of gestational diabetes mellitus. The American Journal of Clinical Nutrition, 2018; 108(3): 603610.

[27] Seldin MM, Meng Y, Qi H, Zhu W, Wang Z, Hazen SL, et al. Trimethylamine N-Oxide Promotes Vascular Inflammation Through Signaling of Mitogen-Activated Protein Kinase and Nuclear Factor-KB. Journal of the American Heart Association, 2016; 5(2): e002767.

[28] Valensise H, Vasapollo B, Gagliardi G, Novelli GP. Early and late preeclampsia: two different maternal hemodynamic states in the latent phase of the disease. Hypertension 2008; 52:873-880.

\section{Tables}

Table 1. Distributions of characteristics between preeclampsia and control groups

\begin{tabular}{cccc}
\hline Characteristics & $\begin{array}{c}\text { PE } \\
(\mathrm{N}=66)\end{array}$ & $\begin{array}{c}\text { Control } \\
(\mathrm{N}=198)\end{array}$ & $p$ \\
\hline \multicolumn{4}{l}{ Year of education, years } \\
\hline$\leq 12$ & $54(81.80)$ & $136(68.70)$ & 0.040 \\
\hline$>12$ & $12(18.20)$ & $62(31.30)$ & \\
\hline Pre-pregnancy & BMI (Kg/m $\left.{ }^{2}\right)$ & & \\
\hline$<18.5$ & $12(18.18)$ & $32(16.16)$ & 0.842 \\
\hline $18.5-22.9$ & $38(57.58)$ & $122(61.62)$ & \\
\hline$\geq 23$ & $16(24.24)$ & $44(22.22)$ & \\
\hline Active or passive smoking during pregnancy & \\
\hline Yes & $19(28.78)$ & $40(20.20)$ & 0.363 \\
\hline No & $48(70.75)$ & $158(79.80)$ & \\
\hline Fetal gender & & & \\
\hline Male & $38(57.58)$ & $100(50.51)$ & 0.319 \\
\hline Female & $28(42.42)$ & $98(49.49)$ & \\
\hline
\end{tabular}

Abbreviation: PE, preeclampsia; BMI, body mass index.

Table 2. Maternal plasma TMAO concentration during pregnancy among overall subjects $\square \mathrm{N}=264 \square^{*}$ 


\begin{tabular}{|c|c|c|c|}
\hline Characteristic & $\begin{array}{c}\text { T2 plasma TMAO } \\
\left(\mu \mathrm{g} / \mathrm{m}^{3}\right)\end{array}$ & $\begin{array}{c}\text { TD plasma TMAO } \\
\left(\mu \mathrm{g} / \mathrm{m}^{3}\right)\end{array}$ & $\begin{array}{c}\text { Change of TMAO } \\
\qquad\left(\mu \mathrm{g} / \mathrm{m}^{3}\right)\end{array}$ \\
\hline Mean \pm SD & $90.39 \pm 45.91$ & $175.01 \pm 160.97$ & $84.62 \pm 159.32$ \\
\hline Median & 84.80 & 138.60 & 54.13 \\
\hline Minimum & 4.15 & 21.0 & -146.02 \\
\hline Maximum & 305.00 & 1560.00 & 1255.00 \\
\hline First Quartile & 57.58 & 86.30 & 0.00 \\
\hline Third Quartile & 116.36 & 207.04 & 123.04 \\
\hline Spearman Correlation with T2 plasma & 1.00 & $0.09^{*}$ & $-0.37 \square$ \\
\hline \multicolumn{4}{|l|}{ TMAO } \\
\hline Spearman Correlation with TD plasma & 0.09 & 1.00 & $0.87 \square$ \\
\hline TMAO & & & \\
\hline
\end{tabular}

${ }^{*} p=0.157 ; \square p<0.001$

Abbreviation: TMAO, trimethylamine-N-oxide; T2, the second trimester; TD, the time of delivery;

Table 3. Comparison on maternal plasma TAMO concentration between preeclampsia and control groups

* 95\% CIs were estimated with the Hodges-Lehmann method.

† Based on Wilcoxon rank-sum test.

Abbreviation: TMAO, trimethylamine-N-oxide; PE, preeclampsia; EOPE, early onset preeclampsia; LOPE, late onset preeclampsia; T2, the second trimester; TD, the time of delivery; Q1, first quartile; Q3, third quartile; CI, confident interval.

Table 4. Association between preeclampsia and maternal plasma TAMO concentration in the second trimester a: Adjusted for year of education, pre-pregnancy BMI, smoking during pregnancy, fetal gender;

Abbreviation: TMAO, trimethylamine-N-oxide; PE, preeclampsia; EOPE, early onset preeclampsia; LOPE, late onset preeclampsia; OR, odds ratio; CI, confidence interval.

Table 5. Associations between preeclampsia and maternal plasma TMAO concentration at the time of delivery a Adjusted for year of education, pre-pregnancy BMI, smoking during pregnancy, fetal gender; Abbreviation: TMAO, trimethylamine-N-oxide; PE, preeclampsia; EOPE, early onset preeclampsia; LOPE, late onset preeclampsia; OR, odds ratio; CI, confidence interval. 


\begin{tabular}{|c|c|c|c|}
\hline Group & $\begin{array}{l}\text { T2 plasma TMAO } \\
\text { (median (Q1, Q3), } \\
\left.\mu \mathrm{g} / \mathrm{m}^{3}\right)\end{array}$ & $\begin{array}{l}\text { TD plasma TMAO (median (Q1, } \\
\left.\text { Q3), } \mu \mathrm{g} / \mathrm{m}^{3}\right)\end{array}$ & $\begin{array}{c}\text { Change of TMAO } \\
\text { (median (Q1, Q3), } \\
\left.\mu \mathrm{g} / \mathrm{m}^{3}\right)\end{array}$ \\
\hline \multirow[t]{2}{*}{ Control (N=198) } & $84.05(60.44$ & $134.96(78.10,202.15)$ & 53.71(-2.60, \\
\hline & 113.90) & & 115.52) \\
\hline \multirow[t]{2}{*}{$\mathrm{PE}(\mathrm{N}=66)$} & $92.40(53.80$ & $151.01(103.45,280.48)$ & $57.47(8.32$ \\
\hline & 126.36) & & 211.50) \\
\hline Difference with control ( & $7.45(-6.92,21.83)$ & $33.25(8.54,57.97)$ & $24.36(-9.11,57.84)$ \\
\hline \multicolumn{4}{|l|}{$95 \% \mathrm{CI})^{*}$} \\
\hline$p \dagger$ & 0.296 & 0.010 & 0.167 \\
\hline \multirow[t]{2}{*}{ EOPE $(N=17)$} & $72.30(54.58$ & $370.00(132.37,514.86)$ & 297.70(34.63, \\
\hline & 109.66) & & $454.05)$ \\
\hline Difference with control ( & $-2.62(-23.44$ & $191.25(52.33,330.16)$ & 196.49(63.67, \\
\hline $95 \% \mathrm{CI})^{*}$ & 18.19) & & $329.31)$ \\
\hline$p \dagger$ & 0.791 & $<0.001$ & $<0.001$ \\
\hline \multirow[t]{2}{*}{ LOPE $(\mathrm{N}=49)$} & 93.30( 53.80, & $138.71(101.66,207.00)$ & $30.63(0.00,122.42)$ \\
\hline & 149.00) & & \\
\hline Difference with control ( & $12.33(-5.03,29.70)$ & $14.55(-11.16,40.28)$ & $-4.66(-37.17,27.84)$ \\
\hline \multicolumn{4}{|l|}{$95 \% \mathrm{CI}) *$} \\
\hline$p \dagger$ & 0.162 & 0.245 & 0.766 \\
\hline \multirow[t]{2}{*}{ Mild PE $(\mathrm{N}=41)$} & 103.45(53.80, & $138.71(100.68,207.08)$ & $34.63(-1.03$ \\
\hline & 149.00) & & 130.69) \\
\hline Difference with control ( & $13.71(-6.17,33.60)$ & $15.00(-13.00,43.02)$ & $-3.70(-40.44,33.04)$ \\
\hline \multicolumn{4}{|l|}{$95 \% \mathrm{CI})^{*}$} \\
\hline$p \dagger$ & 0.170 & 0.275 & 0.819 \\
\hline \multirow[t]{2}{*}{ Sever PE $(N=25)$} & $85.10(54.60$ & $168.24(128.14,476.65)$ & $85.23(27.96$ \\
\hline & 109.66) & & 340.35) \\
\hline Difference with control ( & $0.15(-17.69,17.99)$ & $78.93(26.88,130.98)$ & $88.10(21.03$ \\
\hline $95 \% \mathrm{CI}) *$ & & & 155.17) \\
\hline
\end{tabular}




\section{Additional Files}

Additional file 1: Methods for Plasma TMAO concentration assay

Additional file 2: Table S1. Comparison on maternal plasma TAMO concentration between preeclampsia and control groups

\section{Supplementary Files}

This is a list of supplementary files associated with this preprint. Click to download.

- appendix.docx 


\begin{tabular}{|c|c|c|c|c|c|c|}
\hline \multirow[t]{2}{*}{ PE type } & \multicolumn{4}{|c|}{$\begin{array}{l}\text { Quartile for TMAO concentration in the second trimester } \\
\qquad\left(\mu \mathrm{g} / \mathrm{m}^{3}\right)\end{array}$} & \multirow[t]{2}{*}{$\begin{array}{l}p \text { for } \\
\text { trend }\end{array}$} & \multirow[t]{2}{*}{$\begin{array}{r}\text { Per } 50 \mu \mathrm{g} / \mathrm{m}^{3} \\
\text { increment }\end{array}$} \\
\hline & $\begin{array}{c}\text { Q1 } \\
(<57.58)\end{array}$ & $\begin{array}{c}\text { Q2 } \\
(57.58- \\
<84.80)\end{array}$ & $\begin{array}{c}\text { Q3 } \\
(84.80- \\
<116.36)\end{array}$ & $\begin{array}{c}\text { Q4 } \\
(\geq 116.36)\end{array}$ & & \\
\hline \multicolumn{7}{|l|}{$\mathrm{PE}$} \\
\hline $\begin{array}{l}\text { Case / } \\
\text { Control }\end{array}$ & $21 / 45$ & $9 / 57$ & $14 / 52$ & $22 / 44$ & & \\
\hline OR $(95 \% \mathrm{CI})$ & Reference & $\begin{array}{r}0.34(0.14 \\
0.81)\end{array}$ & $\begin{array}{r}0.58(0.26 \\
1.27)\end{array}$ & $\begin{array}{r}1.07(0.52 \\
2.22)\end{array}$ & 0.611 & $1.33(0.98,1.79)$ \\
\hline $\begin{array}{l}\mathrm{OR}_{\text {adj }}^{\mathrm{a}} \\
(95 \% \mathrm{CI})\end{array}$ & Reference & $\begin{array}{r}0.30(0.12 \\
0.75)\end{array}$ & $\begin{array}{r}0.57(0.24 \\
1.32)\end{array}$ & $\begin{array}{r}1.00(0.47 \\
2.14)\end{array}$ & 0.867 & $1.23(0.90,1.68)$ \\
\hline \multicolumn{7}{|l|}{ EOPE } \\
\hline $\begin{array}{l}\text { Case / } \\
\text { Control }\end{array}$ & $6 / 45$ & $3 / 57$ & $4 / 52$ & $4 / 44$ & & \\
\hline OR $(95 \% \mathrm{CI})$ & Reference & $\begin{array}{r}0.40(0.09 \\
1.67)\end{array}$ & $\begin{array}{r}0.58(0.15 \\
2.17)\end{array}$ & $\begin{array}{r}0.68(0.18 \\
2.58)\end{array}$ & 0.643 & $0.89(0.47,1.67)$ \\
\hline $\begin{array}{l}\mathrm{OR}_{\text {adj }}^{\mathrm{a}} \\
(95 \% \mathrm{CI})\end{array}$ & Reference & $\begin{array}{r}0.34(0.08 \\
1.53)\end{array}$ & $\begin{array}{r}0.52(0.13 \\
2.18)\end{array}$ & $\begin{array}{r}0.66(0.16 \\
2.65)\end{array}$ & 0.372 & $0.75(0.39,1.44)$ \\
\hline \multicolumn{7}{|l|}{ LOPE } \\
\hline $\begin{array}{l}\text { Case / } \\
\text { Control }\end{array}$ & $15 / 45$ & $6 / 57$ & $10 / 52$ & $18 / 44$ & & \\
\hline OR $(95 \% \mathrm{CI})$ & Reference & $\begin{array}{r}0.32(0.11 \\
0.88)\end{array}$ & $\begin{array}{r}0.58(0.24 \\
1.41)\end{array}$ & $\begin{array}{r}1.23(0.55 \\
2.74)\end{array}$ & 0.389 & $1.48(1.06,2.05)$ \\
\hline $\begin{array}{l}\mathrm{OR}_{\text {adj }}^{\mathrm{a}} \\
(95 \% \mathrm{CI})\end{array}$ & Reference & $\begin{array}{r}0.40(0.16 \\
1.00)\end{array}$ & $\begin{array}{r}0.61(0.24 \\
1.56)\end{array}$ & $\begin{array}{r}1.12(0.48 \\
2.59)\end{array}$ & 0.521 & $1.41(1.00,1.98)$ \\
\hline \multicolumn{7}{|l|}{ Mild PE } \\
\hline $\begin{array}{l}\text { Case / } \\
\text { Control }\end{array}$ & $14 / 45$ & $4 / 57$ & $7 / 52$ & $16 / 44$ & & \\
\hline OR $(95 \% \mathrm{CI})$ & Reference & $\begin{array}{r}0.23(0.07 \\
0.73)\end{array}$ & $\begin{array}{r}0.43(0.16 \\
1.17)\end{array}$ & $\begin{array}{r}1.17(0.51 \\
2.68)\end{array}$ & 0.497 & $1.55(1.09,2.20)$ \\
\hline $\begin{array}{l}\mathrm{OR}_{\text {adj }}^{\mathrm{a}} \\
(95 \% \mathrm{CI})\end{array}$ & Reference & $\begin{array}{r}0.25(0.05 \\
1.19)\end{array}$ & $\begin{array}{r}0.43(0.15 \\
1.30)\end{array}$ & $\begin{array}{r}1.19(0.50 \\
2.86)\end{array}$ & 0.510 & $1.35(0.69,2.64)$ \\
\hline \multicolumn{7}{|l|}{ Severe PE } \\
\hline $\begin{array}{l}\text { Case / } \\
\text { Control }\end{array}$ & $7 / 45$ & $5 / 57$ & $7 / 52$ & $6 / 44$ & & \\
\hline OR $(95 \% \mathrm{CI})$ & Reference & $\begin{array}{r}0.56(0.17 \\
1.90)\end{array}$ & $\begin{array}{r}0.87(0.28 \\
2.66)\end{array}$ & $\begin{array}{r}0.88(0.27 \\
2.82)\end{array}$ & 0.999 & $0.98(0.58,1.66)$ \\
\hline
\end{tabular}


0.53(0.15,

0.89(0.26,

0.71(0.20,

0.550

$0.83(0.48,1.43)$

(95\%CI)

1.87)

2.97)

2.50) 


\begin{tabular}{|c|c|c|c|c|c|c|}
\hline \multirow[t]{2}{*}{ PE type } & \multicolumn{4}{|c|}{ Quartile for TMAO concentration in the third trimester $\left(\mu \mathrm{g} / \mathrm{m}^{3}\right)$} & \multirow{2}{*}{$\begin{array}{l}p \text { for } \\
\text { trend }\end{array}$} & \multirow{2}{*}{$\begin{array}{c}\text { Per } 50 \mu \mathrm{g} / \mathrm{m}^{3} \\
\text { increment }\end{array}$} \\
\hline & $\begin{array}{c}\text { Q1 } \\
(<86.30)\end{array}$ & $\begin{array}{c}\text { Q2 } \\
(86.30- \\
<138.60)\end{array}$ & $\begin{array}{c}\text { Q3 } \\
(138.60- \\
<207.04)\end{array}$ & $\begin{array}{c}\text { Q4 } \\
(\geq 207.04)\end{array}$ & & \\
\hline \multicolumn{7}{|l|}{$\mathrm{PE}$} \\
\hline $\begin{array}{l}\text { Case / } \\
\text { Control }\end{array}$ & $8 / 57$ & $22 / 45$ & $14 / 52$ & $22 / 44$ & & \\
\hline OR (95\%CI) & Reference & $\begin{array}{r}3.48(1.42 \\
8.56)\end{array}$ & $\begin{array}{r}1.92(0.74 \\
4.94)\end{array}$ & $\begin{array}{r}3.56(1.45 \\
8.76)\end{array}$ & 0.033 & $1.23(1.09,1.37)$ \\
\hline $\begin{array}{l}\mathrm{OR}_{\mathrm{adj}}^{\mathrm{a}} \\
(95 \% \mathrm{CI})\end{array}$ & Reference & $\begin{array}{r}3.62(1.39 \\
9.43)\end{array}$ & $\begin{array}{r}2.10(0.80 \\
5.55)\end{array}$ & $\begin{array}{r}4.25(1.62 \\
11.10)\end{array}$ & 0.018 & $1.24(1.09,1.40)$ \\
\hline \multicolumn{7}{|l|}{ EOPE } \\
\hline $\begin{array}{l}\text { Case / } \\
\text { Control }\end{array}$ & $1 / 57$ & $5 / 45$ & $1 / 52$ & $10 / 44$ & & \\
\hline OR (95\%CI) & Reference & $\begin{array}{r}6.33(0.71 \\
56.16)\end{array}$ & $\begin{array}{r}1.10(0.07 \\
17.98)\end{array}$ & $\begin{array}{r}12.96(1.60 \\
105.04)\end{array}$ & 0.008 & $1.59(1.29,1.96)$ \\
\hline $\begin{array}{l}\mathrm{OR}_{\text {adj }}^{\mathrm{a}} \\
(95 \% \mathrm{CI})\end{array}$ & Reference & $\begin{array}{r}5.76(0.64 \\
52.27)\end{array}$ & $\begin{array}{r}1.15(0.09 \\
14.88)\end{array}$ & $\begin{array}{r}14.86(1.66 \\
129.85)\end{array}$ & 0.010 & $1.62(1.29,2.03)$ \\
\hline \multicolumn{7}{|l|}{ LOPE } \\
\hline $\begin{array}{l}\text { Case / } \\
\text { Control }\end{array}$ & $7 / 57$ & $17 / 45$ & $13 / 52$ & $12 / 44$ & & \\
\hline OR (95\%CI) & Reference & $\begin{array}{r}3.08(1.17 \\
8.06)\end{array}$ & $\begin{array}{r}2.04(0.75 \\
5.49)\end{array}$ & $\begin{array}{r}2.22(0.81 \\
6.11)\end{array}$ & 0.273 & $1.12(0.99,1.27)$ \\
\hline $\begin{array}{l}\mathrm{OR}_{\mathrm{adj}}^{\mathrm{a}} \\
(95 \% \mathrm{CI})\end{array}$ & Reference & $\begin{array}{r}3.41(1.21 \\
9.56)\end{array}$ & $\begin{array}{r}2.23(0.80 \\
6.22)\end{array}$ & $2.70(0.93,7.85)$ & 0.190 & $1.12(0.98,1.28)$ \\
\hline
\end{tabular}

Mild PE

Case /

7/ 57

$13 / 45$

$10 / 52$

$11 / 44$

Control

OR (95\%CI) Reference

2.35(0.87,

$1.57(0.56, \quad 2.04(0.73,5.68)$

0.319

$1.14(1.00,1.31)$

6.39)

4.41)

$\mathrm{OR}_{\text {adj }}^{\mathrm{a}}$

Reference

2.16(0.75,

1.83(0.62,

2.61(0.87,

0.184

$1.16(1.00,1.35)$

(95\%CI)

$6.24)$

5.39)

7.83)

Severe PE

Case /

$1 / 57$

$9 / 45$

4/ 52

$11 / 44$

Control

OR (95\%CI) Reference 11.39(1.39,

93.27)

4.39(0.48,

14.25(1.77,

0.015

$1.40(1.18,1.67)$

$\mathrm{OR}_{\text {adj }}^{\mathrm{a}}$

Reference $\quad 12.25(1.41$,

$40.50)$

114.59)

4.42(0.48,

14.37(1.74,

0.019

$1.41(1.17,1.70)$ 
